\title{
Enhanced mRNA cap methylation increases Cyclin D1 expression and promotes cell transformation
}

\author{
VH Cowling \\ Division of Cell Biology and Immunology, College of Life Sciences, University of Dundee, Dundee, UK
}

Cap-dependent mRNA translation requires the methylation of the mRNA guanosine cap by RNA guanine7-methyltransferase (RNMT). mRNA cap methylation was recently described to be rate-limiting for a subset of mRNAs, and to be enhanced by expression of c-Myc and E2F1, although the biological significance of this finding was not investigated. Here, it is reported that increased RNMT expression enhances cellular mRNA cap methyltransferase activity, promotes mammary epithelial cell transformation and cooperates with H-RasV12 or c-Myc to promote fibroblast cell transformation. Cyclin D1 is a prominent oncogene in epithelial tumours. A significant fraction of Cyclin D1 mRNA was found to be unmethylated on the mRNA cap and thus dormant in mammary epithelial cells. Cyclin D1 expression was increased by enhanced mRNA cap methylation. In summary, this report shows that $m R N A$ cap methylation is rate-limiting for expression of an oncogene and cell transformation. Oncogene (2010) 29, 930-936; doi:10.1038/onc.2009.368; published online 16 November 2009

Keywords: Cyclin D1; cell transformation; mRNA cap methylation; mRNA translation

\section{Introduction}

RNA polymerase II gene products undergo a series of modifications that are essential for efficient gene expression, including addition of the 5',7-methylguanosine cap (Shatkin, 1976; Shuman, 2002). In mammals, RNGTT (RNA guanylyltransferase and 5'-phosphatase) catalyses the capping reaction, which is the hydrolysis of the triphosphate of the first transcribed nucleotide and the addition of GMP to produce the mRNA guanosine cap, $5^{\prime} \mathrm{GpppX}$, where $\mathrm{X}$ is the first transcribed nucleotide (Furuichi and Shatkin, 2000). The cap protects mRNA from attack by exonucleases. A second enzyme, RNMT (RNA guanine-7-methyltransferase) catalyses the methylation of the guanosine cap at the seventh position to produce the 7-methylgua-

Correspondence: Dr VH Cowling, Division of Cell Biology and Immunology, College of Life Sciences, University of Dundee, Dow Street, Dundee DD1 5EH, UK.

E-mail: v.h.cowling@dundee.ac.uk

Received 8 December 2008; revised 19 August 2009; accepted 28 September 2009; published online 16 November 2009 nosine cap, $5^{\prime} \mathrm{m} 7 \mathrm{GpppX}$. Methylation of the cap is required for efficient eIF4E binding and subsequent eIF4F complex formation, which is critical for mRNA binding to the $40 \mathrm{~S}$ ribosomal subunit and initiation of translation (Gingras et al., 1999; Furuichi and Shatkin, 2000). The 7-methylguanosine cap also promotes splicing, nuclear export and polyA addition, although the extent to which this is observed appears to be gene and species specific. The majority of capping reactions occur co-transcriptionally, and both RNGTT and RNMT are recruited preferentially to the phosphorylated form of RNA polymerase II that is found at the initiation of transcription (Bentley, 2005).

Recent reports have described that a subset of mRNAs exist in the cell that are capped but not methylated, and that cap methylation of these mRNAs can be upregulated by c-Myc and E2F1 transcription factors (Cowling and Cole, 2007; Cole and Cowling, 2009). Most $c-M y c$ transcriptional target genes and a subset of other genes were found to be upregulated by this mechanism and therefore, upregulation of mRNA cap methylation was proposed, but not proven, to be a significant effector of c-Myc in promoting cell proliferation and cell transformation (Cole and Cowling, 2008).

The Saccharomyces cerevisiae and human mRNA cap methyltransferases, $A D B 1$ and RNMT, are essential for cell viability (Mao et al., 1995; Shafer et al., 2005; Chu and Shatkin, 2008). However, it was not known whether endogenous RNMT is rate-limiting for mRNA translation and whether elevation of cap methyltransferase activity has an impact on cellular functions. In this report, RNMT is shown to be rate-limiting for cellular cap methyltransferase activity, and enhancing this activity promotes Cyclin D1 expression and cell transformation.

\section{Results}

RNMT increases $m R N A$ cap methyltransferase activity To increase mRNA cap methyltransferase activity, TERT-immortalized human mammary epithelial cells (IMEC) were transduced by retroviral infection with the human RNMT gene, fused to green fluorescent protein (GFP; Wen and Shatkin, 2000; DiRenzo et al., 2002). Following retroviral infection, pools of cells were drugselected and RNMT was detected by western blot (Figure 1a). The mRNA cap methyltransferase activity of the IMEC line extracts was measured. Cell extracts 
were incubated with guanosine-capped, in vitro transcribed RNA and the methyl donor, $S$-adenosylmethionine. The resultant cap methylation of the in vitro transcribed RNA was detected by thin layer chromatography (Pillutla et al., 1998; Figure 1b). Expression of RNMT-GFP resulted in a fourfold increase in cap methyltransferase activity compared with the GFP control. As GFP is a large protein that may potentially alter the activity and action of proteins to which it is fused, the same experiment was carried out using RNMT fused to the 10 amino-acid haemagglutinin (HA) tag. HA-RNMT expression in IMEC was also found to increase mRNA cap methyltransferase activity (Supplementary Figures $1 \mathrm{~A}$ and B).

To confirm that cellular mRNA cap methyltransferase activity is dependent on RNMT, RNMT expression

a
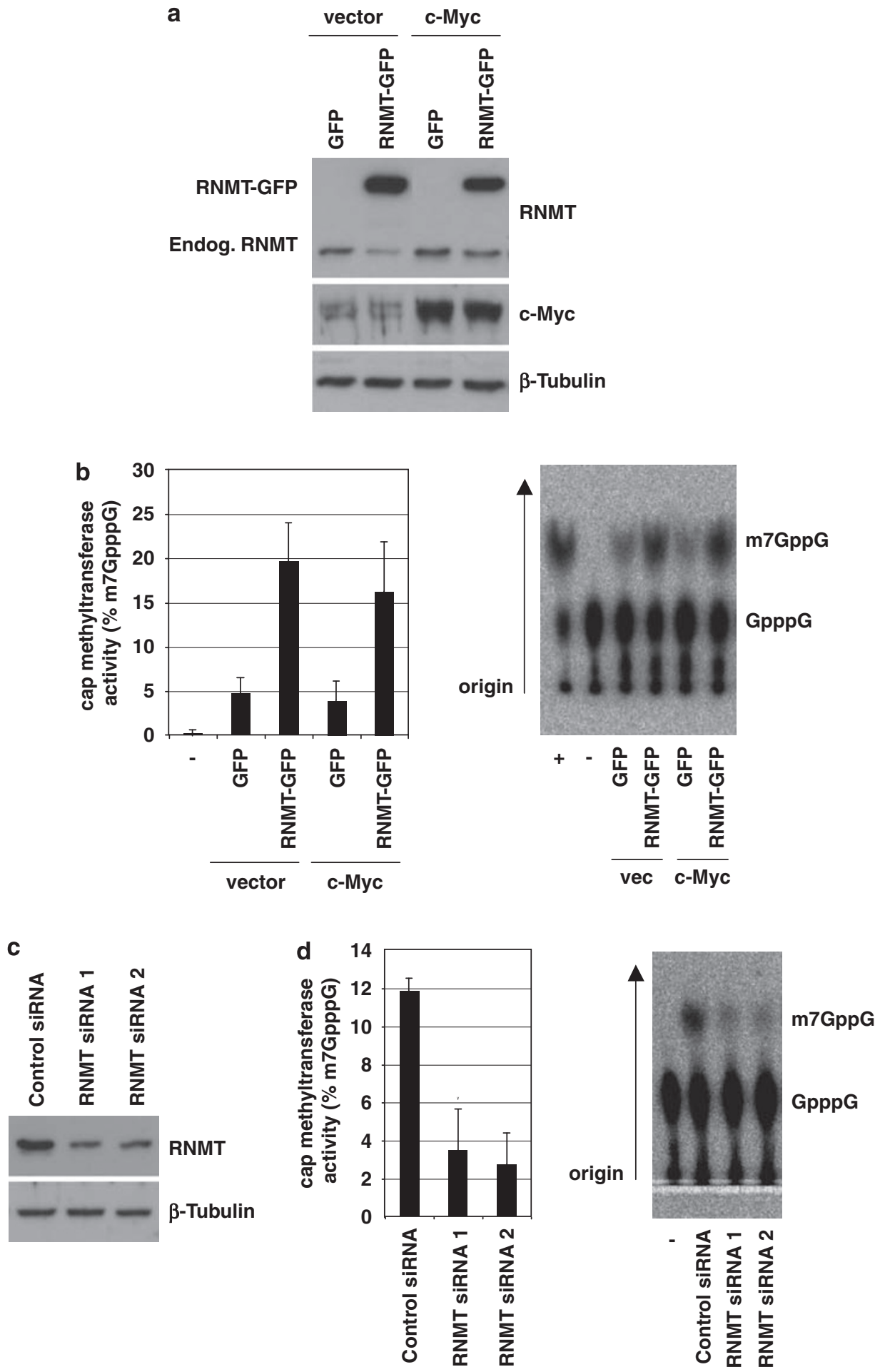

Figure 1 
was inhibited by transfection of two independent siRNAs (Figure 1c). Inhibition of endogenous RNMT expression resulted in a corresponding reduction in mRNA cap methyltransferase activity (Figure 1d). This confirms that RNMT is the major mRNA cap methyltransferase in IMEC.

c-Myc has been reported to enhance mRNA cap methylation of specific mRNAs (Cowling and Cole, 2007; Cole and Cowling, 2009), and therefore the effect of elevated c-Myc expression on RNMT expression and cellular cap methyltransferase activity was investigated. The panel of IMEC lines was transduced with a c-Myc expression construct or vector control by retroviral infection and pools of cells were drug-selected. Elevated c-Myc expression did not result in changes in RNMT expression or total cellular cap methyltransferase activity (Figures $1 \mathrm{a}$ and b; Supplementary Figures 1A and B). Therefore c-Myc-induced mRNA cap methylation is not a result of increased RNMT expression or total cellular RNMT activity.

\section{RNMT transforms human mammary epithelial cells}

The impact of elevated RNMT expression on cell proliferation and cell transformation was investigated. Elevated RNMT-GFP and HA-RNMT expression did not result in increased cell proliferation of plated cells (not shown), but did result in enhanced cell transformation (Figures 2a and b; Supplementary Figure 1C). Cell transformation was assessed by measuring the ability of the IMEC lines to proliferate in an anchorage-independent manner in the soft agar transformation assay. IMEC lines have been shown previously to be unable to proliferate in suspension unless they have elevated expression of an oncogene such as c-Myc (Cowling et al., 2007). After 7 days incubation in suspension, the size of the resultant colonies was measured (Figure 2b), and after 14 days, micrographs of the IMEC lines were taken (Figure 2a). In accordance with previous publications, vector control IMEC did not proliferate in an anchorage-independent manner, whereas elevated c-Myc expression resulted in $12 \%$ of plated cells proliferating into significant colonies (larger than $60 \mu \mathrm{m}$ in diameter). Expression of RNMT-GFP also resulted in $16 \%$ of plated cells growing into significant colonies, and combined exogenous expression of c-Myc and RNMT resulted in $33 \%$ of plated cells growing into significant colonies. The transformation assays were also performed using IMEC expressing RNMT-HA, with similar results to those obtained using RNMT-GFP (Supplementary Figure 1C).

\section{RNMT enhances Ras- and c-Myc-induced cell transformation}

To expand on these findings, a similar set of transformation assays were performed in Rat1A cells, which are also unable to proliferate in an anchorage-independent manner unless they have elevated expression of an oncogene. In this set of experiments, RNMT was exogenously expressed in combination with c-Myc, H-RasV12, an activated Ras mutant or vector control. After 7 days growth in suspension the size of the resultant colonies was measured (Figure 2d), and light micrographs were taken (Figure 2c). As expected, exogenous expression of c-Myc and H-RasV12 resulted in significant anchorage-independent colony growth (45 and $72 \%$ plated cells growing into colonies larger than $60 \mu \mathrm{m}$ in diameter, respectively). Exogenous expression of RNMT did result in a small increase in anchorage-independent colony growth, although this was not statistically significant. Expression of RNMT, however, did significantly increase the number of c-Mycinduced colonies larger than $60 \mu \mathrm{m}$ in diameter from 45 to $76 \%$ of plated cells, and increased the number of H-Ras V12-induced colonies larger than $120 \mu \mathrm{m}$ in diameter from 12 to $36 \%$ of plated cells.

\section{RNMT promotes Cyclin D1 translation}

The implication of the finding that RNMT promotes cell transformation is that a gene or genes that are ratelimiting for cell transformation have increased mRNA cap methylation and mRNA translation in response to RNMT expression. Mammary tumours are associated with increased expression of several oncogenes, including c-Myc, Ras and Cyclin D1, which were potential

\footnotetext{
Figure 1 Increased RNMT (RNA guanine-7-methyltransferase) expression increases cellular mRNA cap methyltransferase activity. (a) Whole cell extracts from the IMEC (TERT-immortalized human mammary epithelial cell) lines indicated were analysed by western blot for expression of RNMT, RNMT-GFP, c-MYC and $\beta$-tubulin. The migration of endogenous RNMT and RNMT-GFP is indicated. Cells were lysed in Triton lysis buffer ( $10 \mathrm{~mm}$ Tris (pH 7.05), $50 \mathrm{~mm} \mathrm{NaCl}, 30 \mathrm{~mm} \mathrm{Na}$ pyrophosphate, $50 \mathrm{~mm} \mathrm{NaF}, 5 \mu \mathrm{m}$ $\mathrm{ZnCl}_{2}, 10 \%$ glycerol, $0.5 \%$ Triton X-100, $10 \mu \mathrm{m}$ leupeptin, $1 \mu \mathrm{m}$ pepstatin and $0.1 \mathrm{mg} / \mathrm{ml}$ aprotinin). Polyclonal anti-RNMT antibodies were raised against full-length recombinant GST-RNMT in sheep and affinity-purified and other antibodies were purchased from Santa Cruz Biotechnologies (Santa Cruz, CA, USA). (b) The same extracts were analysed for their cap methyltransferase activity. Assay was adapted from Pillutla et al. (1998). A 55 base strand of in vitro transcribed RNA was capped using vaccinia virus capping enzyme and ${ }^{32} \mathrm{P} \alpha$-GTP according to the manufacturer's instructions (Epicentre Biotechnologies, Madison, WI, USA). G ${ }^{32} \mathrm{P}-\mathrm{RNA}$ (10$40 \mathrm{ng}$ ) was incubated with $2 \mu \mathrm{g}$ cell extract in $10 \mu \mathrm{l} 50 \mathrm{~mm}$ Tris $(\mathrm{pH} 8), 6 \mathrm{~mm} \mathrm{KCl}, 1.25 \mathrm{~mm} \mathrm{MgCl} 2,100 \mathrm{~nm} S$-adenosylmethionine at $37^{\circ} \mathrm{C}$ for $10 \mathrm{~min}$. RNA was purified, precipitated and re-suspended in $4 \mu \mathrm{l} 50 \mathrm{~mm}$ NaAcetate and $0.25 \mathrm{U} \mathrm{P} 1$ nuclease for $30 \mathrm{~min}$ at $37^{\circ} \mathrm{C}$. Cap (GpppG) and methyl-cap (m7GpppG) were resolved in $0.4 \mathrm{~m}$ ammonium sulphate thin layer chromatography using PEI cellulose plates. Standards were visualized by UV light to establish correct migration. Labelled spots were visualized and quantified by autoradiography, and percentage conversion of GpppG to $\mathrm{m} 7 \mathrm{GppG}$ was calculated. Average results for three independent experiments are shown and error bars indicate the standard deviation. A representative assay is also shown including a negative control ( - ), in which no extract was added and a positive control (+), in which recombinant RNMT was added. (c) IMEC were transfected with two independent siRNAs directed against RNMT or Cyclophilin B (negative control), according to the manufacturer's instructions (Dharmacon Inc., Lafayette, CO, USA). After $24 \mathrm{~h}$, cell extracts were prepared and analysed for their cap methyltransferase activity, as above, except $4 \mu \mathrm{g}$ of cell extract was used. (d) The extracts from (c) were analysed for cap methyltransferase activity using the method described in (b).
} 

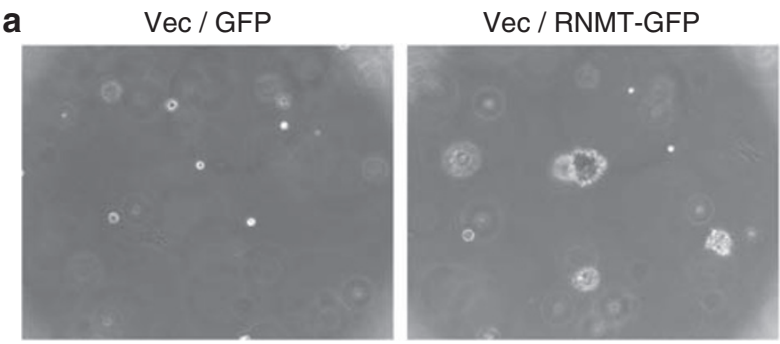

c-Myc / GFP

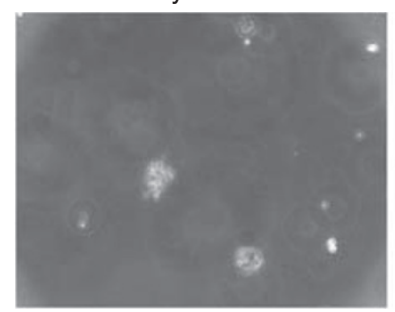

c-Myc / RNMT-GFP
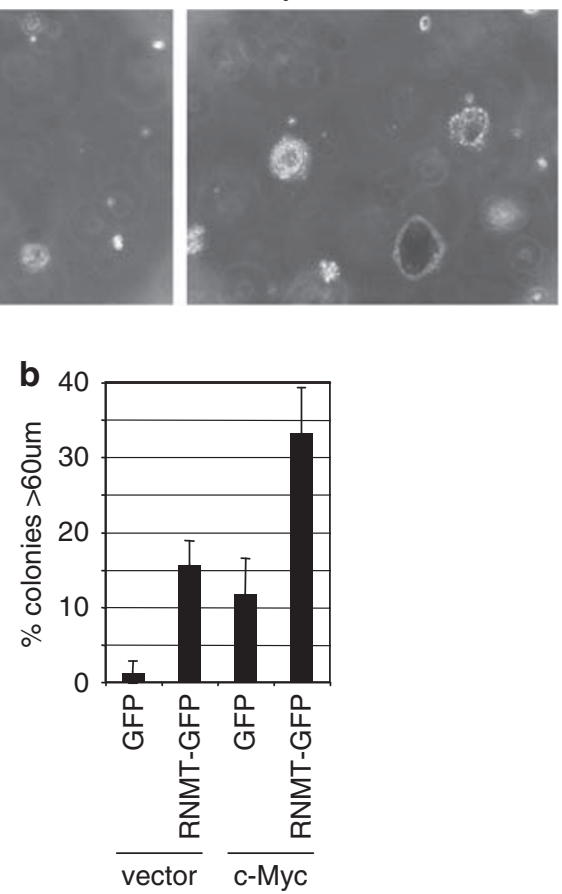

C

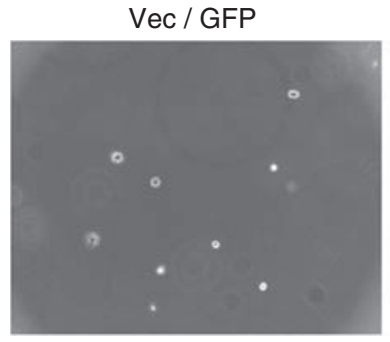

c-Myc / GFP

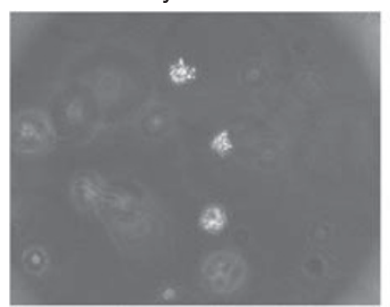

RAS / GFP
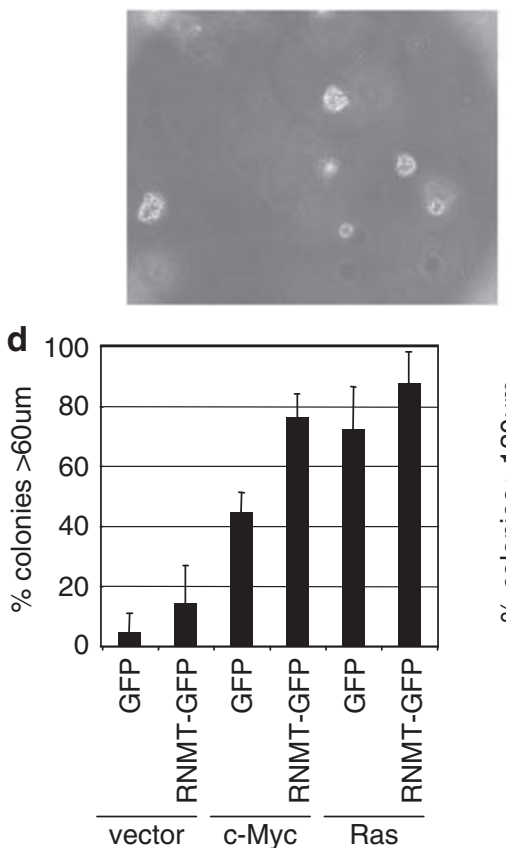

Vec / RNMT-GFP

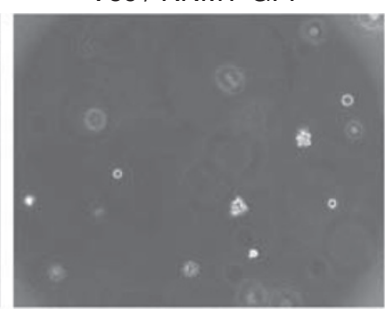

c-Myc / RNMT-GFP

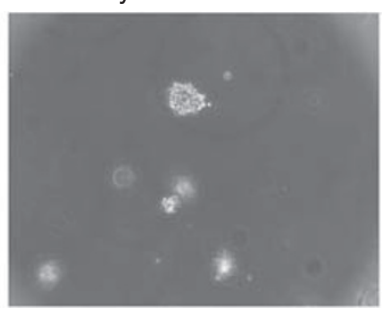

RAS / RNMT-GFP
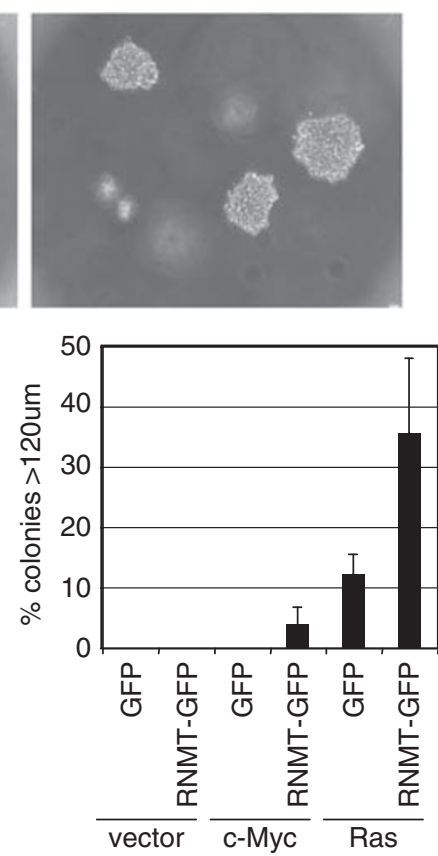

Figure 2 RNA guanine-7-methyltransferase (RNMT) promotes cell transformation. (a, b) IMEC (TERT-immortalized human mammary epithelial cells) and (c, d) Rat1A fibroblasts expressing the proteins indicated were used in the soft agar transformation assay, performed according to Cowling et al. (2006) with the following modifications. A total of $2.5 \times 10^{4}$ IMEC per ml were plated in $0.3 \%$ noble agar/IMEC medium supplemented with $5 \%$ fetal bovine serum (FBS; Invitrogen, Carlsbad, CA, USA). Cells were fed with $250 \mu \mathrm{I}$ IMEC medium per 5\% FBS every second day, starting with the day of plating. Rat1A cells were plated in Dulbecco's modified Eagle's medium (DMEM) per 10\% FCS and fed every fourth day, starting with the day of plating. (a, c) Micrographs of colonies at 14 and 7 days, respectively. (b, d) After 7 days the size of colonies was measured for 100 plated cells using a graticule. Chart depicts the percentage of cells developing into colonies of the size indicated at 7 days. Average results for three independent experiments are shown and error bars indicate the standard deviation.

candidates for regulation at the level of cap methylation in the RNMT-expressing mammary epithelial cell (IMEC) line. c-Myc and Ras protein levels were unresponsive to elevated RNMT expression (Figure 1a; data not shown), however, Cyclin D1 protein was induced in response to RNMT-GFP (Figure 3a) and HA-RNMT expression (Supplementary Figure 1A). (Cyclin D1 is a Myc-repressed gene (Philipp et al., 1994), and a reduction in Cyclin D1 protein levels was observed in the c-Myc-expressing cell lines (Figures 3a and b).) Total Cyclin D1 mRNA levels were not induced in response to RNMT (Figure 3b), but the level of Cyclin D1 m7G (methyl capped) mRNA was upregulated threefold (Figure 3c). mRNA cap methylation was determined by anti-7-methylguanosine antibody immunoprecipitation of $\mathrm{m} 7 \mathrm{G}$ mRNA followed by Cyclin-D1-specific reverse transcription (RT)-PCR (Cole and Cowling, 2009). The substrate for the anti- 
a
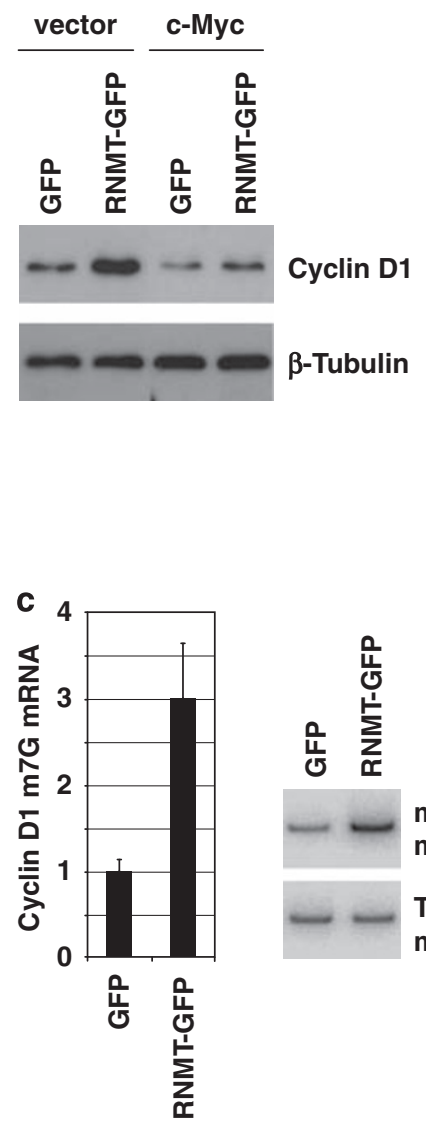
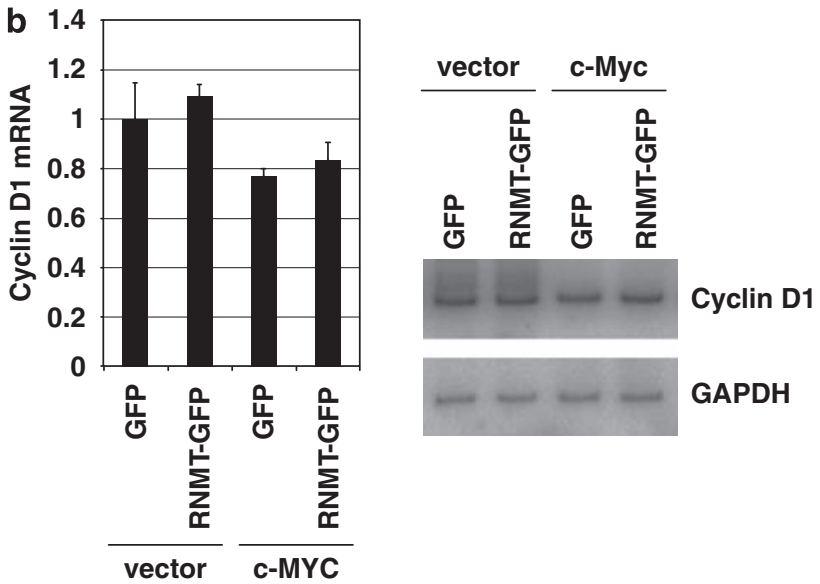

GAPDH

m7G Cyclin D1

mRNA

Total Cyclin D1 mRNA
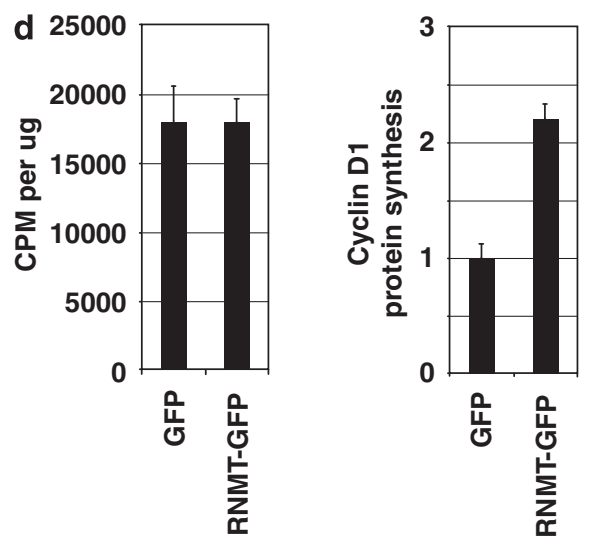

Figure 3 RNA guanine-7-methyltransferase (RNMT) promotes Cyclin D1 mRNA cap methylation and translation. All experiments were performed in the TERT-immortalized human mammary epithelial cell (IMEC) lines indicated. (a) Expression of Cyclin D1 and $\beta$-tubulin was analysed by western blot. (b) Cyclin D1 mRNA levels were determined by reverse transcription (RT)-PCR performed using Superscript One Step RT-PCR System (Invitrogen). Reactions were labelled using ${ }^{32} \mathrm{P}$ labelled-primers, resolved by gel electrophoresis and quantified by phosphoimager. A representative gel is shown. Reactions were determined to be in the linear range by performing a titration of input mRNA. Reactions were normalized to rRNA levels because the cellular rRNA content was unchanged in response to expression of RNMT. (c) Cyclin D1 m7G mRNA levels were determined by anti-m7G antibody immunoprecipitation followed by RT-PCR, in the cell lines indicated, performed according to Cole and Cowling (2009). A representative gel is shown. (d) The IMEC lines were labelled with ${ }^{35} S$-cysteine and methionine and incorporation per $\mu \mathrm{g}$ protein extract and into Cyclin D1 was determined. IMEC plates $(10 \mathrm{~cm})$ were incubated in $4 \mathrm{ml}$ regular growth medium minus cysteine and methionine containing $10 \mu \mathrm{M}$ MG132 for $30 \mathrm{~min}$ at $37^{\circ} \mathrm{C}$. Express Protein Labeling Mix containing ${ }^{35} \mathrm{~S}$-cysteine and methionine $(220 \mu \mathrm{Ci}$; PerkinElmer, Waltham, MA, USA) was added for $15 \mathrm{~min}$. Cells were lysed, normalized for protein content, and ${ }^{35} S$-cysteine and methionine incorporation into TCA-precipitated protein was detected using a scintillation counter. Immunoprecipitations performed on half of each extract using $2.5 \mu$ polyclonal anti-Cyclin D1 or control polyclonal antibodies were resolved by gel electrophoresis. Label incorporation into Cyclin D1 was detected by phosphoimager and expressed as values relative to input. For all charts, average results for three independent experiments are shown and error bars indicate the standard deviation.

methylguanosine immunoprecipitation was highly purified cellular RNA, which is free from binding proteins and therefore RNA interaction with the antibody is dependent on the guanosine cap being methylated, rather than a binding protein masking the methylguanosine epitope. Similar results were also gained by expression of HA-RNMT (Supplementary Figures 1D and $\mathrm{E})$. The rate of Cyclin D1 protein synthesis was measured in the IMEC lines by incubation with radiolabelled amino acids. These experiments were performed in the presence of the proteasome inhibitor, MG132, using conditions that had previously been established to inhibit Cyclin D1 degradation (not shown). Amino-acid incorporation into total acid- precipitable material did not alter in response to elevated RNMT expression, indicating that total protein synthesis was unaffected (Figure 3d). However, when Cyclin D1 was immunoprecipitated from the same extracts and label incorporation was measured, Cyclin D1 protein synthesis was found to be upregulated in response to RNMT expression, which correlated with the observed increase in Cyclin D1 m7G mRNA levels and protein expression (Figure 3d).

The experiments described above show that elevated RNMT expression results in increased Cyclin D1 mRNA cap methylation and protein expression. To further validate the relationship between RNMT and Cyclin D1, we inhibited expression of endogenous 


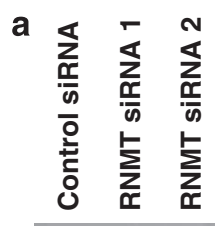
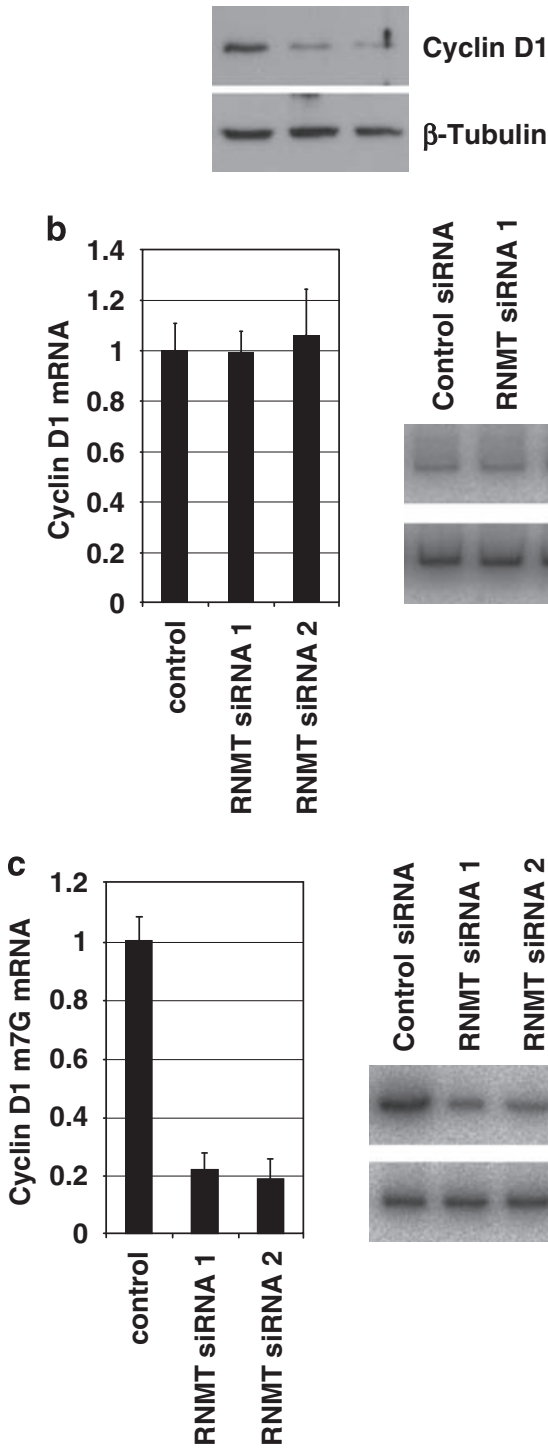

Figure 4 RNA guanine-7-methyltransferase (RNMT) is necessary for Cyclin D1 mRNA cap methylation and translation. IMEC were transfected with two independent siRNAs directed against RNMT or Cyclophilin B (negative control), as in Figure 1. After $24 \mathrm{~h}$, cells were lysed and protein and RNA were extracted. (a) Whole cell extracts were analysed by western blot for expression of RNMT, Cyclin D1 and $\beta$-tubulin. RNA was analysed for relative expression level of (b) total Cyclin D1 mRNA and (c) Cyclin D1 m7G mRNA. Representative gels are shown. For all charts, average results for three independent experiments are shown and error bars indicate the standard deviation.

RNMT by transfection of two independent siRNAs (Figure 1c). A reduction in RNMT expression correlated with reduced Cyclin D1 mRNA cap methylation (Figure 4c) and reduced expression of Cyclin D1 protein (Figure 4a). However, reduced RNMT expression had no effect on Cyclin D1 mRNA levels (Figure 4b).
Therefore, endogenous RNMT is necessary for Cyclin D1 mRNA cap methylation and protein expression.

\section{Discussion}

In this report, RNMT is shown to be rate-limiting for mRNA cap methyltransferase activity and cell transformation. Of note, elevated expression of RNMT in TERT-IMEC was sufficient to transform an equivalent number of cells as elevated expression of c-Myc (Figure 2). RNMT and mRNA cap methyltransferase activities have not been previously reported to be transforming or oncogenic, and future work will be focused on investigating the expression and activity of RNMT in tumours. In support of a role for RNMT in oncogenesis, elevated RNMT mRNA expression level was noted in adrenal, bladder, liver and lung carcinomas relative to normal tissue in ONCOMINE (www. oncomine.org), a web-based microarray database and data-mining platform (Rhodes et al., 2004).

Many recent reports have correlated an increase in total protein synthesis with cell transformation (Pandolfi, 2004; White, 2008). However, the rate of total protein synthesis was not altered in response to RNMT expression, and therefore the pro-transforming effect of RNMT in mammary epithelial cells is likely to be mediated by a restricted number of biologically significant mRNAs. Cyclin D1, an oncogene which is overexpressed in 40 $90 \%$ of cases of invasive breast cancer (Roy and Thompson, 2006), was found to be induced in response to RNMT expression, correlating with increased mRNA cap methylation and translation (Figure 3). Therefore, a significant proportion of Cyclin D1 mRNA is not methylated on the $5^{\prime}$ guanosine cap and thus is dormant in epithelial cells, and can be rapidly activated and translated by upregulation of mRNA cap methylation. Cyclin D1 is the first example of oncogene expression being regulated at the level of mRNA cap methylation.

In this report, RNMT and c-Myc cooperate to promote mammary epithelial cell transformation (Figure 2). Cyclin D1 is transcriptionally repressed by c-Myc, and the minor elevation in Cyclin D1 levels in response to RNMT in the c-Myc/IMEC is unlikely to make a significant contribution to cell transformation. Other examples of biologically significant mRNAs have been reported to be upregulated by mRNA cap methylation, and these are potential candidates for mediating Myc-RNMT co-transformation. These include most c-Myc transcriptional target genes, which were shown to be the targets for Myc-dependent mRNA cap methylation (Cole and Cowling, 2009). Among these are genes that have been implicated in or shown to promote cell transformation or tumorigenesis, including eIF4E (Wendel et al., 2004, 2007), Nol5a (Goy et al., 2006; Vallat et al., 2007) and HSP60 (Tsai et al., 2008).

\section{Conflict of interest}

The author declares no conflict of interest. 


\section{Acknowledgements}

I thank Mike Cole for the generous gift of the anti-m7G antibodies, Aaron Shatkin for providing the RNMT-GFP construct, Julian

\section{References}

Bentley DL. (2005). Rules of engagement: co-transcriptional recruitment of pre-mRNA processing factors. Curr Opin Cell Biol 17: 251-256.

Chu C, Shatkin AJ. (2008). Apoptosis and autophagy induction in mammalian cells by small interfering RNA knockdown of mRNA capping enzymes. Mol Cell Biol 28: 5829-5836.

Cole MD, Cowling VH. (2008). Transcription-independent functions of MYC: regulation of translation and DNA replication. Nat Rev Mol Cell Biol 9: 810-815.

Cole MD, Cowling VH. (2009). Specific regulation of mRNA cap methylation by the c-Myc and E2F1 transcription factors. Oncogene 28: 1169-1175.

Cowling VH, Chandriani S, Whitfield ML, Cole MD. (2006). A conserved Myc protein domain, MBIV, regulates DNA binding, apoptosis, transformation, and G2 arrest. Mol Cell Biol 26: 4226-4239.

Cowling VH, Cole MD. (2007). The Myc transactivation domain promotes global phosphorylation of the RNA polymerase II carboxy-terminal domain independently of direct DNA binding. Mol Cell Biol 27: 2059-2073.

Cowling VH, D'Cruz CM, Chodosh LA, Cole MD. (2007). c-Myc transforms human mammary epithelial cells through repression of the Wnt inhibitors DKK1 and SFRP1. Mol Cell Biol 27: 5135-5146.

DiRenzo J, Signoretti S, Nakamura N, Rivera-Gonzalez R, Sellers W, Loda $\mathrm{M}$ et al. (2002). Growth factor requirements and basal phenotype of an immortalized mammary epithelial cell line. Cancer Res 62: 89-98.

Furuichi Y, Shatkin AJ. (2000). Viral and cellular mRNA capping: past and prospects. Adv Virus Res 55: 135-184.

Gingras AC, Raught B, Sonenberg N. (1999). eIF4 initiation factors: effectors of mRNA recruitment to ribosomes and regulators of translation. Annu Rev Biochem 68: 913-963.

Goy A, Stewart J, Barkoh BA, Remache YK, Katz R, Sneige N et al. (2006). The feasibility of gene expression profiling generated in fineneedle aspiration specimens from patients with follicular lymphoma and diffuse large B-cell lymphoma. Cancer 108: 10-20.

Mao X, Schwer B, Shuman S. (1995). Yeast mRNA cap methyltransferase is a 50-kilodalton protein encoded by an essential gene. Mol Cell Biol 15: 4167-4174.
Downward for providing the H-RasV12 construct and James DiRenzo for providing IMEC. I also thank all of the above and the Cowling lab for advice. This work was funded by an MRC Career Development Award and a Tenovus Scotland Project Grant.

Pandolfi PP. (2004). Aberrant mRNA translation in cancer pathogenesis: an old concept revisited comes finally of age. Oncogene 23: 3134-3137.

Philipp A, Schneider A, Vasrik I, Finke K, Xiong Y, Beach D et al. (1994). Repression of Cyclin D1: a novel function of MYC. Mol Cell Biol 14: 4032-4043.

Pillutla RC, Yue Z, Maldonado E, Shatkin AJ. (1998). Recombinant human mRNA cap methyltransferase binds capping enzyme/RNA polymerase IIo complexes. J Biol Chem 273: 21443-21446.

Rhodes DR, Yu J, Shanker K, Deshpande N, Varambally R, Ghosh D et al. (2004). ONCOMINE: a cancer microarray database and integrated data-mining platform. Neoplasia 6: 1-6.

Roy PG, Thompson AM. (2006). Cyclin D1 and breast cancer. Breast 15: 718-727.

Shafer B, Chu C, Shatkin AJ. (2005). Human mRNA cap methyltransferase: alternative nuclear localization signal motifs ensure nuclear localization required for viability. Mol Cell Biol 25: 2644-2649.

Shatkin AJ. (1976). Capping of eucaryotic mRNAs. Cell 9: 645-653.

Shuman S. (2002). What messenger RNA capping tells us about eukaryotic evolution. Nat Rev Mol Cell Biol 3: 619-625.

Tsai YP, Teng SC, Wu KJ. (2008). Direct regulation of HSP60 expression by c-MYC induces transformation. FEBS Lett 582: 4083-4088.

Vallat LD, Park Y, Li C, Gribben JG. (2007). Temporal genetic program following B-cell receptor cross-linking: altered balance between proliferation and death in healthy and malignant B cells. Blood 109: 3989-3997.

Wen Y, Shatkin AJ. (2000). Cap methyltransferase selective binding and methylation of GpppG-RNA are stimulated by importin-alpha. Genes Dev 14: 2944-2949.

Wendel HG, De Stanchina E, Fridman JS, Malina A, Ray S, Kogan S et al. (2004). Survival signalling by Akt and eIF4E in oncogenesis and cancer therapy. Nature 428: 332-337.

Wendel HG, Silva RL, Malina A, Mills JR, Zhu H, Ueda T et al. (2007). Dissecting eIF4E action in tumorigenesis. Genes Dev 21: 3232-3237.

White RJ. (2008). RNA polymerases I and III, non-coding RNAs and cancer. Trends Genet 24: 622-629.

Supplementary Information accompanies the paper on the Oncogene website (http://www.nature.com/onc) 